\title{
DESIGN AND DYNAMIC ANALYSIS OF PERCUSSION ENGRAVING TOOL
}

\author{
Mišél BATMEND, Daniela PERDUKOVÁ \\ Department of Electrical Engineering and Mechatronics, Faculty of Electrical Engineering and Informatics, \\ Technical University of Košice, Letná 9, 04200 Košice, Slovak Republic, tel.: +421 55602 2256, e-mail: misel.batmend@tuke.sk, \\ daniela.perdukova@tuke.sk
}

\begin{abstract}
The proposed paper describes the principles of construction of an electromagnetic diamond percussion tool used for stone engraving. The tool foundation is an electrically driven pointed diamond engraving by hammering on solid, polished surfaces. The paper includes measurements of tool prototype, describing its basic features and potential applications. Finally, the tool performance is tested on a sample image engraved into polished black granite.
\end{abstract}

Keywords: mechatronic system, percussion tool, experimental measurements, headstone engraving, photo etching

\section{INTRODUCTION}

Nowadays, a majority of headstone portraits is handmade, although machine engraving becomes trendy. The machines are XY CNC plotters using either laser tool [7], or milling cutter [2]. The proposed tool demonstrates another way of engraving, relating mostly to methods and tools used for handmade portraits. The handheld tool is usually machine of the type in which alternating electric current is used to bring about the vibratory movement of sharply pointed cutter used for engraving (see [5]). Control of single stroke of the cutter is impossible due to the method of driving of actuating solenoid. This would be useless in terms of handheld tools, but when attempting to use such tool connected to CNC plotter, it turns out to be crucial. Controlling of single strokes allows the plotter to build up a mosaic of dots representing picture or portrait based on black \& white model image.

When driving the solenoid by buck-boost converter, the duration of striking and recovering of tool to its original position can be easily changed. Also the magnitude of current fed to the solenoid can be adjusted. Experimenting with these parameters, rather optimal functionality of the tool can be obtained.

\section{ENGRAVING TOOL DESIGN}

\subsection{Mechanical properties of the tool}

The tool (Fig. 1) compounds of plunger core actuatable by solenoid to conduct the striking operation and a set of spring members to recover the plunger core back to the original position. The lower end of plunger core is equipped with pointed diamond.

The A - upper spring recovers the plunger core after striking operation, the $\mathrm{B}$ - lower spring serves for dumping the back stroke of core while recovering. Moreover, when properly timed, it raises the energy of following stroke. The spring rates are related as follows:

$k_{A}>k_{B}$

\subsection{Dynamic properties of the tool}

Feeding the electric current into the solenoid upraises a magnetic field which causes the ferrite plunger core to
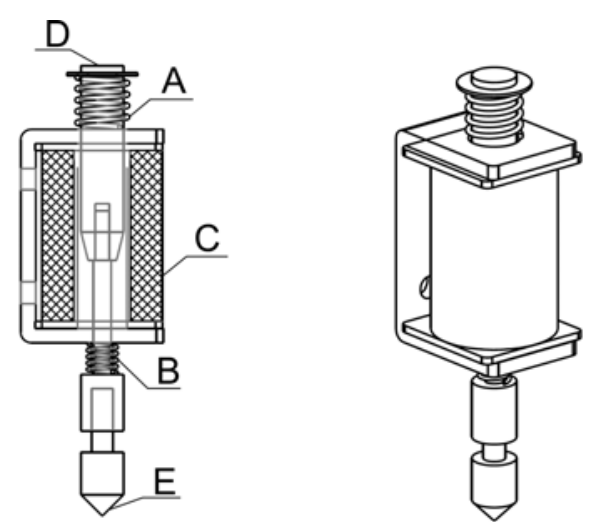

Fig. 1 Percussion tool: A - upper spring, B - lower spring, C solenoid, D - plunger core, $\mathrm{E}$ - pointed diamond

slide into the hole in center of solenoid. Core together with diamond is forced to make a vertical movement. If a polished stone desk is put into specific distance, the diamond will hit the desk which will cause disruption of polished surface. This disruption usually appears as a brighter dot on a darker stone. In this state, the plunger core is in its lowest position, whilst the diamond is touching the desk. The A spring is pressed (see Fig.2 time $\mathrm{t}=0,1 \mathrm{~s})$.

Interrupting the current flow in solenoid will cause the magnetic field to disappear. The A spring will recover the plunger core to its original (or zero) position. The moment of inertia of core together with set of springs A and B will cause the overshoot and oscillation around the original position. Finally the core will reach its steady state, when the forces of both springs equalize. The plunger together with springs behaves as a second order dynamic system, which can be described mathematically by differential equation:

$\frac{d^{2}}{d t^{2}} x(t)+2 \cdot \zeta \cdot \omega_{n} \cdot \frac{d}{d t} x(t)+\omega_{n}^{2} \cdot x(t)=G_{d c} \cdot \omega_{n}^{2} \cdot u(t)$

where:

$x(t)$ - Response of the system

$u(t)$ - Input to system 
$\zeta$ - Damping ratio

$\omega_{\mathrm{n}}$ - Undamped natural frequency

$\mathrm{G}_{\mathrm{dc}}-$ The DC gain of the system

The solution of such equation is well known (see [6]). The system is constrained by the maximum length of stroke and also the material put into the path of moving plunger. Instead of simulations, series of experimental measurements was taken.

Fig. 2 depicts the plot of position of diamond tip performing one stroke. The plot was captured by measuring on prototype tool, constructed according to Fig. 1. As a position measuring device, a linear quadrature sensor detecting $25 \mathrm{impulses} / \mathrm{mm}$ was used. The time base sampling period was equal to $0,819 \mathrm{~ms}$. The sensor was attached to the plunger core in the way that its influence (additional mass) on measurement was minimized.

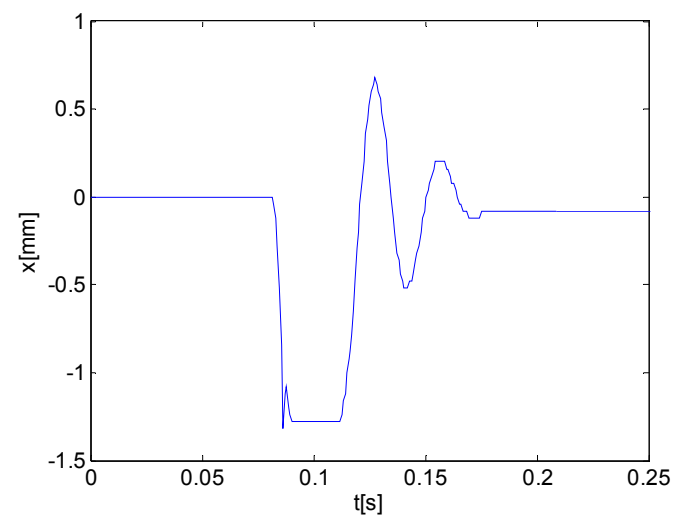

Fig. 2 The diamond tip position during one stroke

As can be seen in a plot, after hitting the desk for the first time, the diamond tip will bounce off and hit the desk again. To disrupt the surface of the desk, energy of the first hit is decisive. Concerning the maximal frequency of strokes, it is sufficient to set the timing, so that the tip will hit the desk only once. The energy of bounce can be then used to help recover the plunger core into zero position (where $\mathrm{x}=0$ ). With appropriate timing, the energy of overshooting core can be also added to following stroke.

\section{DYNAMIC ANALYSIS AND EXPERIMENTAL RESULTS}

To identify the tool maximal percussion frequency and its relation to magnitude of actuating force, set of measurements has been taken. Stroke frequency is relevant parameter, because it has significant influence on overall speed of engraving. One could presuppose that stronger force would allow the core to oscillate faster and vice versa. Adjusting of actuating force is feasible due to a buck - boost converter which is driving the solenoid. Such type of converter is suitable for this application because it allows faster demagnetization of coil compared to simple buck converter.

The detailed schematic of converter is shown in Fig. 3. It includes pair of MOSFET transistors and diodes connected to solenoid represented by inductor and serial resistor. Transistors are driven by high and low side driver with bootstrap circuit. Since the converter is supplied by single voltage source $(24 \mathrm{~V})$, secondary voltages necessary for driver and optocoupler operation $(15 \mathrm{~V}$ and $5.1 \mathrm{~V}$ respectively) are derived using Zener diodes. The converter is driven by external pulse generator which is decoupled by pair of high-speed optocouplers.

The electromagnetic actuating force is proportional to current flowing trough solenoid. The current magnitude is set by modulating the solenoid voltage by PWM with carrier frequency of $10 \mathrm{kHz}$. Time of feeding and nonfeeding of solenoid can be set as well. Adjusting these parameters, following measurements have been taken.

Fig. 4 shows a measurement with voltage duty cycle $\mathrm{d}=0.5$, and switching times $\mathrm{t}_{\text {on }}=8 \mathrm{~ms}$ and $\mathrm{t}_{\text {off }}=9 \mathrm{~ms}$. The first two strokes have longer switching times $\left(\mathrm{t}_{\mathrm{on}}=30 \mathrm{~ms}\right.$, $\mathrm{t}_{\mathrm{off}}=20 \mathrm{~ms}$ ) in order to define a full swing of diamond tip.

Shortening of switching times, while using the same voltage duty cycle leads to strike irregularities (see Fig. 5). The tip does not reach the zero position before a following strike is actuated.

Using a voltage duty cycle $\mathrm{d}=0.5$ yields the maximum percussion frequency:

$f_{d 0.5}=\frac{1}{t_{o n}+t_{o f f}}=\frac{1}{8 \times 10^{-3}+9 \times 10^{-3}}=58.8 \mathrm{~Hz}$

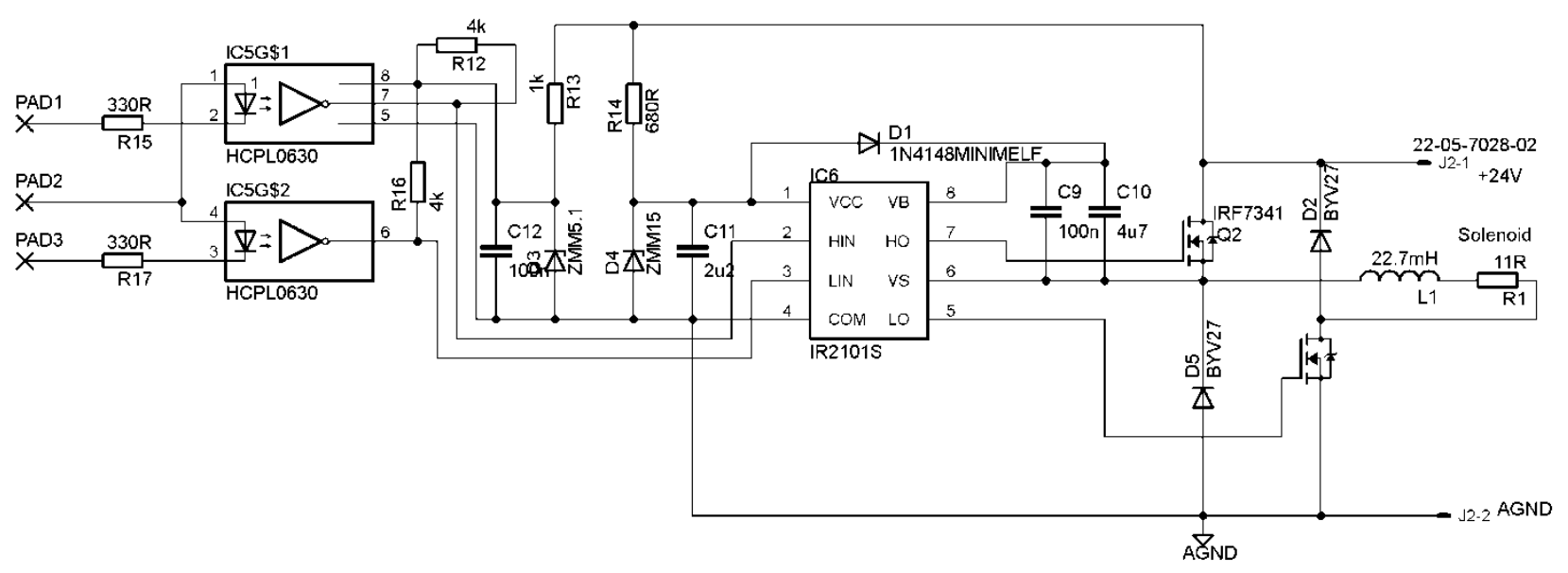

Fig. 3 Buck - boost converter, complete schematic 
Increasing the voltage duty cycle leads to boosting the current flow through solenoid which concludes in rise of magnetic force actuating the plunger core. Thus the stroke on the stone desk is stronger. Therefore a diameter and depth of a bright dot increases. Fig. 6 depicts a measurement with voltage duty cycle $\mathrm{d}=0.7$.

When using the $t_{\text {on }}=8 \mathrm{~ms}$ and $t_{\text {off }}=9 \mathrm{~ms}$, bouncing of the tool tip can be noticed (see Fig. 6). To avoid this effect, shortening of the on time to $t_{o n}=7 \mathrm{~ms}$ is necessary (see Fig. 7).

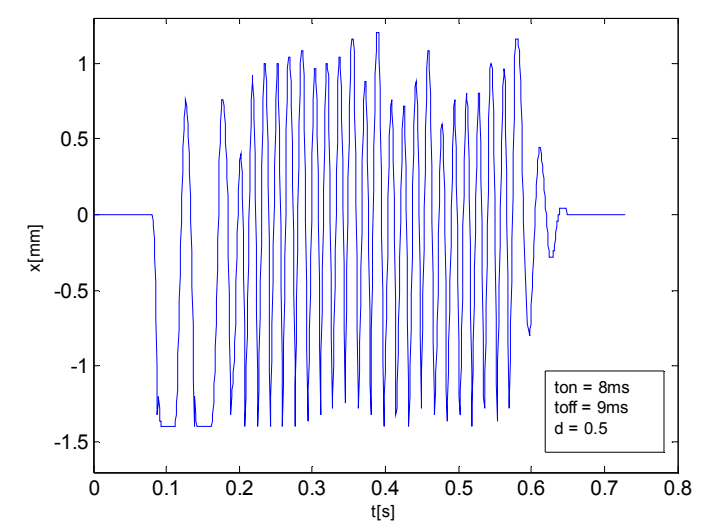

Fig. 4 The diamond tip position. Strokes with duty cycle of 0.5 . Maximal frequency, no overlapping of strokes.

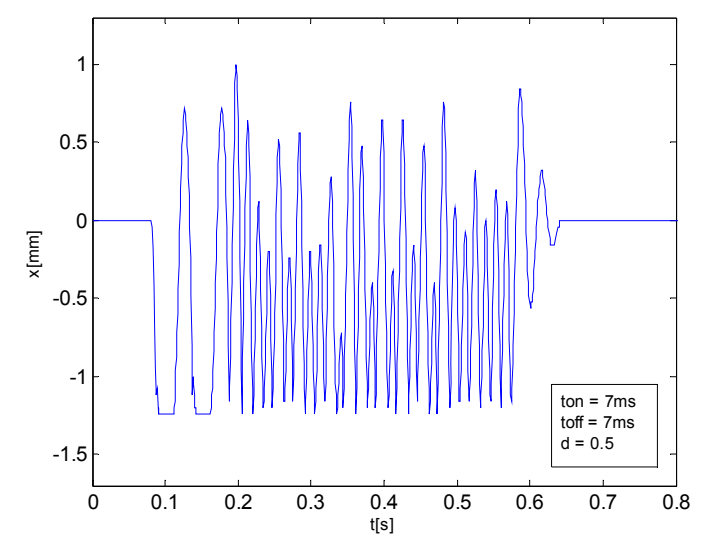

Fig. 5 The diamond tip position. Strokes with duty cycle of 0.5 . Higher frequency causes irregular strokes.

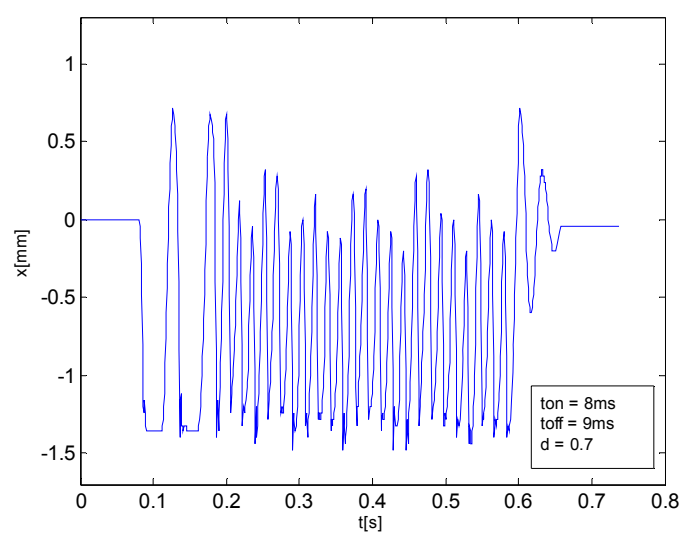

Fig. 6 The diamond tip position. Strokes with duty cycle of 0.7 . Lower frequency causes undesirable bouncing of diamond tip.

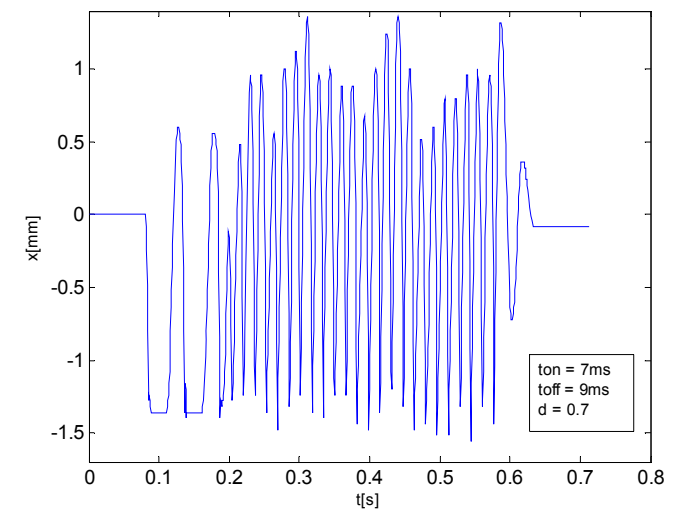

Fig. 7 The diamond tip position. Strokes with duty cycle of 0.7 . Bouncing can be prevented by increasing strike frequency.

Decreasing of voltage duty cycle leads to a softer stroke, which will show as smaller bright dot on the stone desk. When using parameters $\mathrm{d}=0.3, \mathrm{t}_{\mathrm{on}}=8 \mathrm{~ms}$ and $t_{\text {off }}=11 \mathrm{~ms}$, the tool tip does not even reach the desk (Fig. 8), because the on time is too short to let the tip get to the desk. Rising the on and off times solves the problem (Fig. 9). Hence, the strike frequency decreases:

$f_{d 0.3}=\frac{1}{30 \times 10^{-3}}=33.33 \mathrm{~Hz}$

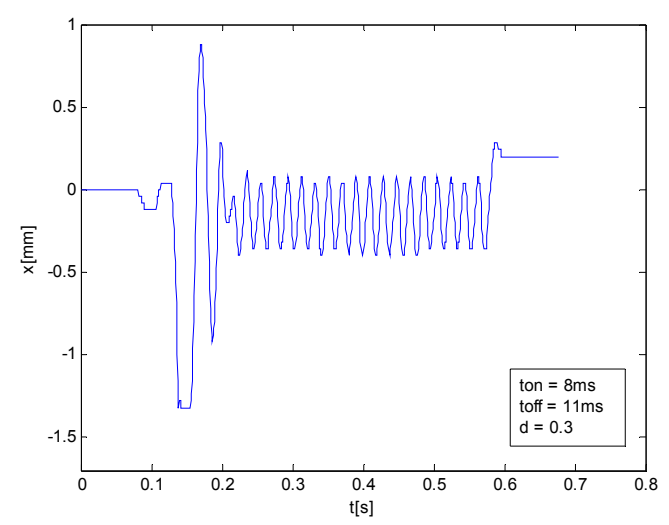

Fig. 8 The diamond tip position. Strokes with duty cycle of 0.3 . The actuating force is too small to let the tool tip get all the way to the stone desk.

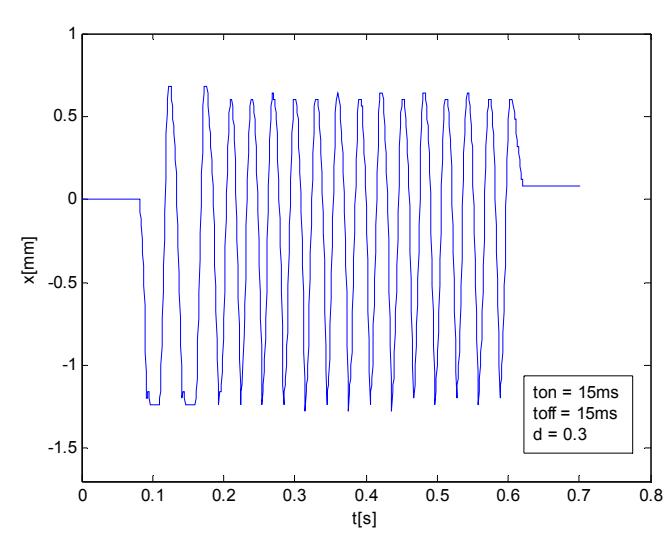

Fig. 9 The diamond tip position. Strokes with duty cycle of 0.3 . Decreasing of frequency enables full swing of the tool tip. 
To test the accuracy of set on and off times corresponding to particular voltage duty cycles, a simple image based on a model image (Fig. 10 a) was engraved. The model image is an 8 bit grayscale. The brightness rises from left to right starting with darkest finishing with brightest. The image was transformed to a binary black \& white by conversion algorithm chosen according to [1]. The halftoning algorithm uses cluster dot dithering method, which was chosen from variety of halftoning methods as a most suitable for stone engraving. Subsequently, the image was engraved three times, each time with different voltage duty cycle and corresponding on and off times. After engraving, the image was daubed with a white paint, which settles in deeper dots and thus enhances a contrast between the image and the stone desk.

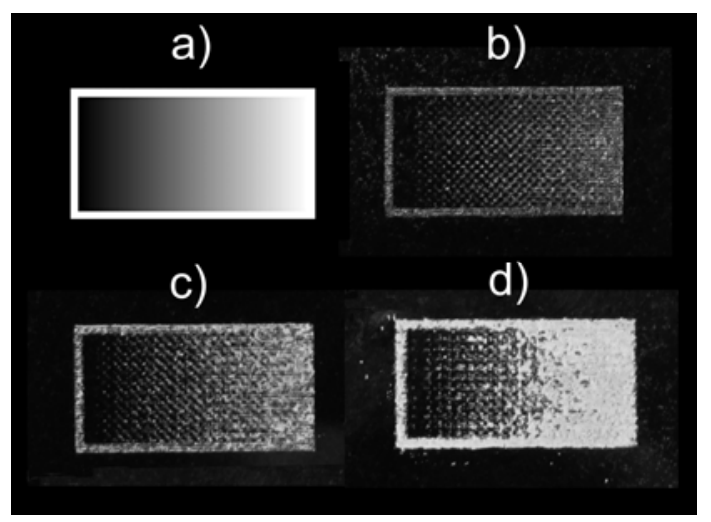

Fig. 10 Image engraved using different voltage duty cycles and on and off times. Scale 1:1.

In Fig. 10 b) a softer stroke, actuated by smaller force (voltage duty cycle $\mathrm{d}=0.3$ ) was used. In Fig. $10 \mathrm{c}$ ) medium stroke was used $(d=0.5)$. Finally in Fig. $10 d)$ stronger stroke was used $(d=0.7)$. Brightness levels of particular images are clearly distinguishable. The darkest image dots are so fine that no paint has settled in. In case (c), bright tones are brighter than in case (b). Transition from dark tones to bright ones is still smooth enough. In case (d), the bright tones are indisputable brightest. On the other hand, the dark-to-bright transition is rough and unsmooth. One can notice some kind of saturation in the bright tones before reaching a maximum brightness. This is caused by overlapping of single dots, since they are too big and create unified piece of white paint even in areas where certain amount of dark dots is expected.

\section{CONCLUSION}

Using detailed analysis and performed experiments with proposed tool we gained a good concept of application capabilities of the tool for engraving portraits into stone desks. We accomplished following conclusions:

1. Size and depth of engraved dot depend mostly on stroke strength. There is only a small influence of duration of stroke on these properties.

2. Duration of stroke should be considered mostly in terms of reaching the maximum frequency of strokes.

Regarding the experiment with engraved image, one can conclude that contrast of engraved image could be enhanced by using variable stroke actuating force. To get as wide scale of tones as possible, the strongest stroke should be also used. Eliminating of bright tones saturation and smoothing of dark-to-bright transition would be necessary.

All the experiments were performed using constant distance of the tool tip from stone desk (approx. $1.3 \mathrm{~mm}$ ). Reducing the distance yields increase in stroke frequency with trade-off of stronger stroke for the dot of the same size. Using distance $1.3 \mathrm{~mm}$ is adequate also because the stone desk is not perfectly flat.

Considering the other tools for engraving, the proposed tool has simple construction and is also cheap. In contrary to milling cutter, it does not wear. When used as a XY plotter tool, the drawback is lower applicable resolution of engraved image (approx. 180dpi). This resolution constraint is introduced by size of the smallest engraved dot which refers to one image pixel. Laser machine resolution is at least $300 \mathrm{dpi}$.

\section{ACKNOWLEDGMENTS}

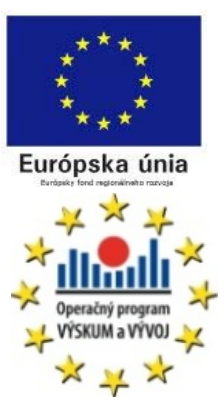

This paper was developed with support of the project Vývoj unikátneho nízkoenergetického statického zdroja pre elektrosystémy, ITMS 26220220029, that is co-financed from Structural funds EU ERDF within Operational programme Research and Development $\mathrm{V}-2008 / 2.2 / 01-\mathrm{SORO}$ and preferred axis 2 Support of Research and Development.

\section{REFERENCES}

[1] BATMEND, M.: An automated headstone photo engraving, 10th Scientific Conference of Young Researchers of Faculty of Electrical Engineering and Informatics Technical University of Košice, I. Edition, pp. 171-173, ISBN 978-80-553-0423-6.

[2] G10 stone image engraving machine. http://www.acmetek.biz/g10.shtml

[3] GONZALEZ, R. C. - WINTZ, P.: Digital image processing.2nd edition, Addison-Wesley publishing company, 1987, ISBN 0-201-11026-1

[4] JARVIS, J. F. - JUDICE, C. N. - NINKE, W. H.: A Survey of Techniques for the Display of Continuous Tone Pictures on Bi-Level Displays, Computer Graphics and Image Processing, vol. 5, pp. 13-40, 1976.

[5] JOHNSON, H. L. K.: Improvements in or relating to Electrically Driven Engraving machines. GB536146, May 1941, Patent specification.

[6] MASTASCUSA, E. J.: An Introduction to system dynamics - Second order systems, http://www.facstaff.bucknell.edu/mastascu/econtrolht $\mathrm{ml} /$ SysDyn/SysDyn2.html\#ImpulseDiffEqn

[7] Z12 Monument Etching Laser.

http://www.kernlasers.com/product_pages/z12.htm 
Received May 3, 2011, accepted October 21, 2011

\section{BIOGRAPHIES}

Mišél Batmend was born on 7.9.1987 in Ulánbátar, Mongolia. He received his M.Sc. degree in Electrical engineering in 2010 from Faculty of Electrical Engineering and Informatics at Technical University in Košice. His research interest included automation of engraving process for specific applications in whole range of its portfolio from hardware level up to image processing.

Daniela Perduková was born in Slovakia, in 1960. She graduated from the Department of Technical Cybernetics at the Faculty of Electrical Engineering, Technical University Kosice, in 1984. She received her Ph.D degree in the field of Electrical Drives and Electrical Traction from the same university in 1995. In 2003 she habilitated. At the present she works as an Associate Professor at the Department of Electrotechnics, Mechatronics and Industrial Engineering at the Faculty of Electrical engineering and Informatics Technical University of Kosice. Her research and educational activities are focused mostly on AI techniques and their applications in the field of continuous lines control; a special attention is also paid to modelling of technological processes, their monitoring and technological process visualization. She has extensive experiences in installing of control and visualization systems in industry. 